\title{
Educational Manifest Destiny: Exclusion, Role Allocation, and Functionalization in Reservation Bordertown District Admission Policies
}

\author{
CHRISTINE ROGERS STANTON \\ Montana State University
}

\begin{abstract}
Towns that border American Indian reservations provide important contexts for studying relationships between educational institutions and marginalized communities. This study applies critical discourse methodologies to evaluate policies from districts bordering reservations, districts geographically distant from reservations, and districts located on reservations. Broadly, the study addresses the question, How do school admission policies perpetuate settler-colonialism? Findings reveal bordertown discourse that excludes Indigenous epistemologies, restricts selfdetermination, and defines the function of knowledge and peoples to reinforce Eurocentric power structures. The study offers implications for policy makers, district leaders, and community members working to enhance equity, particularly given increased pressure for school choice expansion.
\end{abstract}

During the westward expansion of the United States, the doctrine of Manifest Destiny sought to justify forced removal of Indigenous peoples from their lands through fortification of Eurocentric ideals surrounding individualism, settlement, and capitalism (Brayboy 2005). ${ }^{1}$ For hundreds of diverse Indigenous nations, Manifest Destiny did not advance "expansion"—-it signaled a physical and cultural invasion by European and Euro-American settlers and colonists. Within many of today's schools, administrators, school board members, and other "policy insiders" (Bertrand et al. 2015, 3) continue to uphold a form of educational Manifest Destiny through their use of policy discourse that values obedience, individualism, and economic prestige. These settler-colonial definitions of success enact and reinforce institutional racism, which "exists when in-

Electronically published December 14, 2018

American Journal of Education 125 (February 2019)

(C) 2018 by The University of Chicago. All rights reserved.

0195-6744/2019/12502-0003\$10.00 
stitutions or organizations, including educational ones, have standard operating procedures (intended or unintended) that hurt members of one or more races in relation to members of the dominant race" (Scheurich and Young 1997, 5).

The purpose of this study is to evaluate the use of school district policies - in particular, those regulating admission of students not permanently residing within the district boundaries - as a means to reinforce settler-colonial control while limiting Indigenous self-determination. Broadly, this work responds to a call from researchers to investigate the ways "state and local policy changes are furthering racial and economic segregation" (Frankenberg et al. 2017, 459). Specifically, the study considers the questions, How do nonresident student admission policies construct or deconstruct epistemological and ontological borders between schools and Indigenous communities? In what ways does the discourse of these policies encourage or inhibit access and self-determination for Indigenous peoples? How do these policies reinforce settler-colonial power structures?

To address these questions, I analyzed and compared nonresident admission policies from reservation bordertown school districts, reservation-based (RB) school districts, and school districts geographically distant (GD) from reservations. Although the policies analyzed for this study are similar in many ways, the specific discursive choices reflect the deep roots of bias and settler-colonialism, especially in terms of exclusion, role allocation, and institutionally defined function of Indigenous community members. The results of the study reveal bordertown discourse that excludes Indigenous epistemologies and ontologies, restricts Indigenous self-determination, and reinforces Eurocentric power structures. Broadly, the findings demonstrate the pervasiveness of racism within society and the potential for policies, especially those of schools in reservation bordertowns, to reinforce settler-colonialism.

This work is significant to policy makers, educational leaders, caregivers, and advocates for educational equity for several reasons. First, it interrogates the geographic, cultural, political, and educational borders that separate predominantly white institutions from communities of color. In particular, the project contributes to the limited body of research regarding reservation bordertown contexts. The study also advances an important and neglected area of inquiry, given that "the public policy debate, research, and discourse on school choice is

Christine Rogers STANTON is an associate professor of education at Montana State University. Her areas of inquiry focus on advancing social justice, culturally sustaining and revitalizing education, and Indigenous ways of knowing within curricula, pedagogy, policy, and research. 
almost entirely absent a specific engagement with how school choice intersects issues relevant to Indigenous youth and tribal nations" (Castagno et al. 2016, 228). This work is especially timely given the rise of calls for expanded school choice initiatives, which - despite their claims of expanded opportunity for youth of color-tend to encourage segregation (Ahn and McEachin 2017; Knoester and Au 2017; Phillips et al. 2015; Stein 2015). Finally, this study calls for increased institutional accountability to Indigenous communities. Such accountability within research and policy making is important for educational self-determination.

\section{Theoretical Framework: Border Crossing and Tribal Critical Race Theory}

This study draws inspiration from a range of critical theory, especially that which focuses on sovereignty, Indigenous self-determination, and border crossing. These are complicated, intertwined concepts. As Francis and Munson (2017) note, "the idea of sovereignty is complex and wrought with colonial ideology, though the concept has also been subverted by Indigenous people to hold deeper meaning that reflects survival, perseverance, ceremony, tradition, and celebration" (50). Furthermore, the political and policy-making implications associated with educational sovereignty are closely related to what Indigenous scholar Forbes (1998) terms "intellectual sovereignty," or "the state we achieve through a steady struggle for self-determination, a result of many cumulative decisions that we make for ourselves as we move toward self-governance and intellectual self-direction" (15).

"Borderland places" are of particular importance within critical theory and research, as they can serve as "strategic locations for challenge and change" (Porter 2015, 269), especially in terms of thinking about the concepts of sovereignty and self-determination. Within reservation bordertown contexts, Estes (2014b) suggests, "the 'border' in border town functions to exclude those unworthy and to include and protect those who are deemed worthy." Such boundaries are tied to concepts of place, power, and property, which play significant roles in determination, interpretation, and implementation of educational policy. Freire (1985), Anzaldúa (2007), Giroux (1992), and other critical theorists use literal and metaphorical imagery associated with a border crossing to emphasize the complexity of navigation within mainstream sociocultural contexts by marginalized or oppressed peoples.

Critical race theory (CRT; Ladson-Billings and Tate 1995) offers a means to explore border crossing and continued settler-colonialism within policy making. Specifically, awareness of "whiteness as property" (Harris 1993, 1714) forms an 


\section{Educational Manifest Destiny}

important foundation for studying settler-colonialism and racism within education. Whiteness, property, and whiteness as property all played, and continue to play, roles within the design and continued influence of US settler-colonial ideology. Tribal enrollment, which confirmed nonwhiteness, justified seizure of land through the "system of property rights in land in which the 'race' of the Native Americans rendered their first possession rights invisible" (Harris 1993, 1721). In addition, whiteness established more than physical property rights - it also allowed for academic, economic, and political privileges. Estes (2014b) situates whiteness as property within contemporary reservation bordertowns: "Whiteness becomes a form of property that must be defended and valorized. It seeks inclusion as well as exclusion. It demarcates social boundaries. Those who trespass must be punished as if they violated property rights. Border towns ... are the epitome of such thinking."

To further refine CRT's applications within Indigenous contexts, I apply tenets of Brayboy's (2005) tribal CRT (TribalCrit; table 1). Although each tenet is unique and independently important, they can be grouped into three categories when framing this study. Each of these areas is further explored, as situated within the research literature related to settler-colonialism, Indigenous education, self-determination, and cultural revitalization.

TABLE 1

TribalCrit Tenets

\section{Tenet}

1. Colonization is endemic to society.

2. US policies toward Indigenous peoples are rooted in imperialism, white supremacy, and a desire for material gain.

3. Indigenous peoples occupy a liminal space that accounts for both the political and racialized natures of our identities.

4. Indigenous peoples have a desire to obtain and forge tribal sovereignty, tribal autonomy, self-determination, and self-identification.

5. The concepts of culture, knowledge, and power take on new meaning when examined through an Indigenous lens.

6. Governmental policies and educational policies toward Indigenous peoples are intimately linked around the problematic goal of assimilation.

7. Tribal philosophies, beliefs, customs, traditions, and visions for the future are central to understanding the lived realities of Indigenous peoples, but they also illustrate the differences and adaptability among individuals and groups.

8. Stories are not separate from theory; they make up theory and are, therefore, real and legitimate sources of data and ways of being.

9. Theory and practice are connected in deep and explicit ways such that scholars must work toward social change.

SOURCE.-Brayboy (2005). 
Settler-Colonialism and Assimilative Education

TribalCrit's first two tenets argue that "colonization is endemic to society" and "US policies toward Indigenous peoples are rooted in imperialism, white supremacy, and a desire for material gain" (Brayboy 2005, 429). The Indian Removal Act of 1830 forced Indigenous peoples to relocate to reservations, which were, at the time, often the least desirable and least economically valuable lands in the country. Given their access to water, gold, and other resources, the value of many of these lands increased dramatically over time. The US government responded by shrinking reservations and passing the Dawes Act of 1887, which divided reservation lands into individual allotments and allowed the sale of allotments to non-Natives. Population growth, shifting settlement patterns, access to resources, and increased desirability of land near reservations intensified conflicts with bordering towns.

In addition to physical control of Indigenous lands, the federal, state, and local governments sought intellectual control of Indigenous peoples. The sixth tenet of TribalCrit, which argues "governmental policies and educational policies toward Indigenous peoples are intimately linked around the problematic goal of assimilation" (Brayboy 2005, 429), emphasizes the role of government and schools in the effort to force Indigenous children into settler-colonial society. During the boarding school era in the United States, which extended from the late 1800 s to the 1970s, Indigenous children were separated from their families and sent to schools that were often located far from their communities and where they were forced to wear European-style clothing, cut their hair, learn mainstream American lessons, and provide labor, all while being prohibited from speaking their Indigenous languages and exercising traditional practices (Castagno et al. 2016; Lomawaima and McCarty 2006). In addition to cultural oppression, boarding school students were subjected to physical and sexual violence, and the effects of these experiences remain vivid for today's boarding school survivors and throughout Indigenous communities. As a result, many contemporary Indigenous peoples find schools uncomfortable and even dangerous places.

After over a century of efforts, it is clear that settler-colonial, assimilative education has largely failed Indigenous communities. Of all ethnic groups in the United States, today's Indigenous youth are least likely to graduate from high school (Quijada Cerecer 2013). Carjuzaa et al. (2015) note that the achievement gap between Native and non-Native students is especially substantial in schools bordering reservations. Although contemporary educational reform efforts that emphasize "market-based choice, standards, and accountability" (Frankenberg et al. 2017, 449) appeal to "most middle- and upper-class Americans who believe that their status is the result of a well-earned, level playing field of a meritocracy" (Cornbleth 2006, 208), these policies are often biased against 
students of color (Penfield and Lee 2010; Rogers-Ard et al. 2012). Within schools that serve Indigenous students, in particular, Quijada Cerecer (2013) notes, "Policies and rules implemented by the school leadership manifest in a hidden curriculum that seeks to socialize students to embrace and legitimize a universal system of knowledge" (609), while assuming a "superiority of white cultural values and communication styles" (592) within schools.

Schools may even use policies focusing on attendance, behavior, and academic progress to push out students who may jeopardize assimilative goals (Doll et al. 2013; Lugg and Shoho 2006). For example, many schools that serve "at risk" youth, including those serving large numbers of Indigenous students, have adopted a "zero-tolerance" approach. Zero-tolerance policies favor strong enforcement to perceived discipline issues, including potential suspension, expulsion, or denied reenrollment (Skiba 2014; Winn and Winn 2015). Although they claim to focus first on establishing safe learning environments, these policies inappropriately target students of color (Anyon et al. 2016; Winn and Winn 2015), with Indigenous youth nearly twice as likely to receive disciplinary referrals as their white peers (Whitford and Levine-Donnerstein 2014). Through zero-tolerance initiatives and related practices, educational policy can become a tool of continued removal or forced assimilation, which can lead to hostile learning environments, erosion of cultural identity, internalized racial inferiority within Indigenous communities, and an increase in the number of dropouts (Henderson et al. 2015; Khalifa et al. 2016; Quijada Cerecer 2013). As Smith (1999) emphasizes, "Assimilation policies in education were intended to provide one way roads out for those indigenous people who 'qualified.' Many did take that road and have never returned" (199).

\section{The Location of Control: Indigenous Liminality in Schools and Bordertowns}

TribalCrit recognizes that Indigenous peoples "occupy a liminal space that accounts for both the political and racialized natures" of their identities (Brayboy 2005, 429). Given their proximity to large populations of Indigenous peoples who retain a sovereign status and valid political and economic power, reservation bordertowns are particularly contentious spaces that reinforce both social and physical liminality for Indigenous peoples (Ambler 2009; Deyhle 1986; Estes 2014a; Perry 2009; Yazzie 2014). Claims to and confusion about sovereignty can amplify bordertown tensions because exclusionary behavior and policy making in borderlands spaces are more pronounced when the size or strength of a racial minority poses a perceived "threat" (Frankenberg et al. 2017, 450) to the majority group. The unique government-to-government relationship assured through tribal sovereignty also generates confusion regarding the role of Indigenous peoples within educational contexts, including those beyond reservation 
borders. As a result, educational policy makers may relegate Indigenous leaders to the edges of policy-making efforts. In bordertown schools, trust between Native community members, teachers, and administrators suffers because predominantly white administrators and faculty frequently exclude or marginalize Indigenous voices and ways of knowing (Williams 2013).

Despite the challenges unique to bordertowns, much of the research in Indigenous education has taken place in reservation-interior communities (McCarty et al. 2006). Generally, educational research tends to emphasize the achievement gap between Native and non-Native students and differences in dropout and graduation rates rather than evaluate institutional roles in creating or sustaining those gaps (Deloria and Wildcat 2001; Lomawaima 2004). Although reservation and bordertown communities face real, significant challenges, highlighting perceived deficits without recognizing the role of settler-colonialism and of nonNative peoples and predominantly white institutions does little to promote sustainable change (Walter and Anderson, 2013). For Indigenous communities, emphasizing gaps instead of community strengths diminishes the right to cultural and educational self-determination as guaranteed through the 1975 Indian Self-Determination and Education Assistance Act (Brayboy 2005; Castagno et al. 2016). Within these communities, educational decision making is informed (or should be informed) by a complex interaction of federal government, state governments, and tribal governments - a reality that uniquely complicates the "legal and policy terrain" (Castagno et al. 2016, 230) surrounding education in and beyond Indian Country.

\section{Advancing Self-Determination: Indigenous Epistemologies and School Choice}

To expand educational equity and antiracist efforts at institutional and systemic levels, policy makers can promote connections between diverse communities and schools (Gay 2000; González et al. 2005; Khalifa et al. 2016) and enact education that is culturally sustaining and revitalizing (McCarty and Lee 2014; Paris 2012). For example, Montana's Indian Education for All mandate requires educators to teach all students about Indigenous experiences and the importance of honoring Indigenous knowledges (Carjuzaa 2012). Unfortunately, culturally sustaining and revitalizing education has not been implemented consistently or systematically, "despite widespread agreement among researchers, educators, and tribal leaders that culturally responsive schooling works and is needed" (Castagno et al. 2016, 239).

Policy making can be used to sustain and revitalize culture, but it can also create de facto segregation in schools, particularly if policy makers listen exclusively to white stakeholders (Siegel-Hawley 2013). Indigenous community members emphasize that white teachers, leaders, and policy makers must cross 
physical and metaphorical borders to engage in collaborative, culturally grounded research and planning with Indigenous peoples (Rogers and Jaime 2010; Smith 1999; Williams 2013). Policies can honor cultural ways of knowing and promote high levels of learning, as long as policy makers commit to sustainable change and partnerships with Indigenous communities (Brayboy and Castagno 2009; Lomawaima and McCarty 2006; Quijada Cerecer 2013; Santamaria and Santamaria 2015).

TribalCrit encourages expanded inclusion of "tribal philosophies, beliefs, customs, traditions, and visions for the future" within research, curriculum, and policy making, given that "the concepts of culture, knowledge, and power take on new meaning when examined through an Indigenous lens" (Brayboy 2005, 429). Specifically, Brayboy argues that stories must be viewed as "real and legitimate sources of data and ways of being" (430). Unfortunately, Indigenous experiences are often excluded from textbooks and standards (Sanchez 2007; Shear et al. 2015; Stanton 2014). Indigenous pedagogies, such as teaching and learning through what First Nations scholar Archibald (2008) calls "storywork," are rarely applied with integrity (Grande 2004). Furthermore, as Indigenous scholar Tuck (2009) explains, when educational research and practice have included Indigenous experiences, they are most often "damage-centered narratives" (415), instead of stories of resilience, power, and change.

In 2006, Lomawaima and McCarty (2006) called for "a return to choice and local control" (40) as a response to the decades of ineffective formal schooling controlled by non-Indigenous policy makers. Although the research on school choice initiatives serving Indigenous communities is extremely limited and focuses mainly on charter schools, "the school choice landscape in Indian Country is robust" and includes public schools, Bureau of Indian Education schools, parochial schools, charter schools, and online programs (Castagno et al. 2016, 228). Indigenous educational scholars emphasize that school choice can advance cultural revitalization and achievement, as long as control lies with Indigenous communities and families (Castagno et al. 2016; McCarty and Lee 2014).

Unfortunately, research suggests most school choice efforts fail to result in increased achievement for most students (Ahn and McEachin 2017; Figlio and Karbownik 2016; Mills et al. 2016). Furthermore, such initiatives can encourage increased racial segregation (Frankenberg et al. 2017; Knoester and Au 2017; Phillips et al. 2015; Stein 2015). Although US Supreme Court decisions prohibit schools from overtly considering racial identity within admissions decision making, other allowable admissions and academic standards encourage white students to "choose" certain schools and students of color to "choose" other schools (Ahn and McEachin 2017; Carlson 2014).

Even in school districts where caregivers and students are able to make choices, administrators, trustees, and other policy insiders most often determine the options. 
For Indigenous communities, effective school choice efforts must recognize tribal sovereignty - which is collective and community oriented - as opposed to individual or focused on the nuclear family (Castagno et al. 2016). Furthermore, school choice discourse itself frequently reinforces settler-colonial ideologies through application of a "market framework," which is particularly "prominent in policy circles" (Castagno et al. 2016, 234). Within these contexts, priority is typically given to programs and models that promise results that will converge with competitive, Eurocentric interests, such as increased test scores. As Castagno et al. (2016) argue, unless Indigenous communities have control over the choices, interests, and "end goals" (241) so that they align with cultural epistemologies, school choice will fall short of advancing self-determination and achievement for Indigenous students.

\section{Method}

This study integrates critical discourse analysis (CDA; Souto-Manning 2014; van Leeuwen 2008) with Indigenous research methodologies (Brayboy et al. 2012; Grande 2008; Kovach 2013; Padgett 2012; Smith 1999) to evaluate the potential for policies to reinforce physical boundaries (e.g., residency discourse), cultural boundaries (e.g., Eurocentric, settler-colonial success discourse), and political boundaries (e.g., power-oriented discourse). Discourse can be defined to include a wide variety of "context-dependent semiotic practices that are situated within specific fields of social action" (Reisigl and Wodak 2009, 89), including written text, visual images, signs and symbols, and spoken language. CDA is particularly well suited as a tool to evaluate the potential for policies to engage damage-centered or deficit discourse as a means to perpetuate inequities (Bertrand et al. 2015).

Scholars across both CDA and Indigenous research methodologies recognize the need for research to drive practical change that advances "emancipatory agendas" (Brayboy et al. 2012, 423), self-determination, and social justice. Within research and education, Indigenous leaders emphasize the importance of responsible inclusion of Indigenous knowledges and ways of knowing, relevance of content and processes as determined by community members, awareness of comprehensive views of relationality within the community, and resulting products or actions that demonstrate reciprocity and accountability (Brayboy et al. 2012; Grande 2008; Kovach 2013; Padgett 2012; Smith 1999; Wilson 2008). Brayboy and colleagues (2012) noted that research can "serve beneficial purposes when it is driven by community interests and undertaken with attention paid to the complexity, resilience, contradiction, and self-determination of these communities" (448). As a non-Indigenous scholar, I do not claim to apply Indigenous research methodologies to the extent envisioned by Indigenous scholars 
and experts. However, as a critical scholar engaged in borderlands research, I recognize my responsibility to enact appropriate elements as guided by Indigenous community members and scholars.

\section{Positionality}

Within critical research, scholars are encouraged to describe their positionality (Milner 2007). In the case of this study and its emphasis on Indigenous selfdetermination, such self-location is particularly important, given my identity as a non-Indigenous (white) scholar. I have long-standing ties to both of the states and several of the communities included in this study. My family settled and has farmed land just beyond a reservation border for several generations. As a child, I attended schools in a town located less than 2 hours from a reservation. Despite the proximity of the family farm and my schools to reservation communities, I do not remember learning about Indigenous peoples aside from a few isolated examples.

My postsecondary and preprofessional experiences included emphases on multicultural perspectives, social justice, and Indigenous education, and it was during my time as a college student that I learned about the resilience of, and the challenges facing, Indigenous peoples in the two states included in this study. From 1999 to 2007, I worked as a teacher, instructional coach, and department head in one of the reservation bordertown communities included in this study. In addition, from 2006 to 2013, I created and taught online courses for a community-developed charter school based on the reservation. This school was launched to provide a local option (the nearest accredited secondary school was 7 miles away), offer a flexible alternative for "at risk" youth in jeopardy of dropping out, and support integration of cultural knowledges and ways of knowing into the curriculum. Given the overlapping time frames for my work in these two settings, I occasionally had students start in the conventional "face-to-face" school and then transfer to the charter school, and vice versa.

During these experiences, I began working with tribal leaders and mentors to enhance cultural responsiveness in both settings. I engaged in community-based professional development and completed graduate coursework specific to Indigenous education. Despite my efforts, within the bordertown district, I encountered institutional-level resistance in terms of both curricular and pedagogical change, and I was often told that all decisions needed to be grounded in extensive, high-quality research. Given the limited research focusing on Indigenous education, particularly in reservation bordertown contexts, one of my Indigenous mentors encouraged me to "go do the research, then." This charge led me to my doctoral studies and my present position as a teacher educator and researcher at a land-grant university. 
As a scholar, I recognize my continued responsibility to communities and schools across both states included in this study. My work builds upon longstanding relationships with the mentors and tribal leaders who have influenced my professional and personal development. Brayboy et al. (2012) note that critical Indigenous research methodologies are "driven by service" (435), and all of my projects emerge from questions raised by community members, including the study highlighted in this article.

Sites

The districts included in this study serve students in grades $\mathrm{K}-12$ and are located in adjacent northern plains states (table 2). Despite their demographic, geographic, and political similarities, the two states have historically viewed Indigenous culture very differently, at least as related to education. State 1 has

TABLE 2

Community Information

\begin{tabular}{|c|c|c|c|}
\hline & Population & $\%$ Native & $\begin{array}{l}\text { Geographic } \\
\text { Information }^{\mathrm{a}}\end{array}$ \\
\hline \multicolumn{4}{|l|}{ Bordertowns: } \\
\hline $\mathrm{BT} a$ (state 1$)$ & 2,200 & 30 & 14 \\
\hline $\mathrm{BT} b$ (state 2) & 7,500 & 12 & 2 \\
\hline $\mathrm{BT} c$ (state 1$)$ & 9,000 & 23 & 13 \\
\hline BT $d$ (state 2) & 10,600 & 15 & $<1$ \\
\hline $\mathrm{BT} e($ state 1$)$ & 66,000 & 7.5 & 10 \\
\hline \multicolumn{4}{|c|}{ Reservation-based communities: } \\
\hline $\mathrm{RB} a$ (state 1$)$ & 2,000 & 94 & 23 \\
\hline $\mathrm{RB} b$ (state 2 ) & 1,700 & 93 & 15 \\
\hline $\mathrm{RB} c($ state 1$)$ & 350 & 100 & 25 \\
\hline $\mathrm{RB} d$ (state 2) & 1,500 & 94 & 25 \\
\hline $\mathrm{RB} e($ state 1$)$ & 650 & 60 & 28 \\
\hline \multicolumn{4}{|c|}{ Geographically distant communities: } \\
\hline $\mathrm{GD} a($ state 1$)$ & 2,000 & $.37^{\mathrm{b}}$ & 180,13 \\
\hline $\mathrm{GD} b$ (state 2) & 6,300 & $1^{\mathrm{b}}$ & 200,24 \\
\hline $\mathrm{GD} c$ (state 1) & 9,300 & 5 & 130,24 \\
\hline $\mathrm{GD} d$ (state 2) & 12,500 & $.8^{\mathrm{b}}$ & 130,18 \\
\hline $\mathrm{GD} e$ (state 1) & 60,000 & 12 & 85,13 \\
\hline
\end{tabular}

a Bordertowns shown as miles from reservation border; reservation-based communities shown as miles from bordertown; geographically distant communities shown as miles from reservation, miles from population draw.

b District demographics specific to Indigenous students were not reported, so town demographic data are used.

FEBRUARY 2019 
implemented a statewide initiative to support integration of Indigenous culture, history, and experience throughout the curriculum for all students, Native and non-Native. At the time of the study, state 2 had no state-level cultural standards or curricula. ${ }^{2}$

For this study, I identified five predominantly white reservation bordertowns ranging in population (from 2,000 to more than 65,000 residents) and location (bordering multiple reservations in two states). To provide comparison, five districts located within reservation boundaries and five districts located more than 80 miles from reservation borders were then selected. The RB districts were chosen due to their geographic proximity to the identified bordertown communities. The GD communities were selected due to their populations, with one community similar in size to each of the bordertown communities included in the sample. In addition, the GD communities were selected because of potential interdistrict transferability (i.e., another $\mathrm{K}-12$ school district is located within 25 miles of each focus GD community). The US Bureau of the Census (2010) provided population and demographic data for the communities in the study, with state and district reports providing student population and demographic data specific to the districts. Geographic data (e.g., district boundaries, distances to reservations, etc.) were collected using the open access, web-based Geographic Information Systems resource ArcGIS (https://www.arcgis.com/).

\section{Data Sources and Analysis}

The nonresident student admission policies from the various districts provided the data for this study. Broadly, these nonresident student admission policies frame admission requirements for students who fall outside of the school's typical population. This focus is particularly important given the frequency with which Native students living beyond bordertown district boundaries apply for nonresident admission to bordertown districts.

A combination of open, situated, and focused coding practices specific to discourse analysis was used to analyze the district policies regarding admission of nonresident students (Fairclough 1992; Gee 2005). I applied van Leeuwen's (2008) CDA guidelines to evaluate policy language that defined "social actors" (e.g., students, caregivers, district trustees, teachers, district leaders) and their activities. To inform my identification of actors and assignment of codes and themes, I drew upon Indigenous and borderlands scholarship, prior communitycentered participatory research, and collaboration with and mentorship from Indigenous community members.

Because the goal of this study is to consider the unique contexts of bordertowns and how those contexts shape policy discourse, state-level compliance language that appeared across district types (i.e., bordertowns, GD communities, and RB

\section{American Journal of Education}


communities) was eliminated from subsequent phases of analysis. For example, multiple districts defined a "nonresident student" using the same phraseology, regardless of geographic location or sociocultural context. During open coding, deviations from the boilerplate discourse were organized by actor category, assigned codes (table 3), and compared (1) within geographic categories (i.e., bordertown $a[\mathrm{BT} a]$ compared with $\mathrm{BT} b$ ), (2) across geographic categories (i.e., bordertown districts compared with RB districts), and (3) within clusters (i.e., a bordertown compared with its nearest RB community and a similarly sized GD community in the same state).

To crystallize and deepen comparisons, each unit of data was then assigned a focused code based on van Leeuwen's (2008) "sociosemantic inventory" (23). For example, discourse that focuses on assumptions about a student's behavioral role was coded as "role allocation," whereas discourse that describes the expected activities for an adult caregiver was coded as "functionalization" (van Leeuwen 2008, 42). These data were again synthesized and compared within and across districts and geographic clusters. For example, I identified differences in the definitions, representations, and activities of adult caregivers between policies from an RB district and its neighboring bordertown district. In addition, I added memos to contextualize the focused codes within theory and research related to settler-colonialism (an example is shown in table 4).

Finally, I formed themes that integrated the focused codes with TribalCrit tenets (Brayboy 2005; table 5). To provide additional trustworthiness in terms of situated, sociocultural meaning, I verified discursive interpretations with Indigenous scholars and community members and modified these based upon feedback. As Gee (2005) argues, "Words have different specific meanings in different contexts of use ... [which are] also integrally linked to and vary across different social and cultural groups" (53).

\section{Results and Discussion}

Analysis of the nonresident student admission policy discourse revealed themes demonstrating three of van Leeuwen's (2008) representational choices. Through (1) exclusion of Indigenous peoples and perspectives, (2) stereotypical and deficitoriented role allocation to restrict self-determination, and (3) functionalization that reinforces settler-colonial power, the policies demonstrate the pervasive and endemic nature of racism within our society and schools, particularly those in reservation bordertowns (TribalCrit tenet 1). Although none of the policies analyzed in this study directly state intent to exclude Indigenous youth or force assimilation into settler-colonial society, bordertown policies tend to privilege Eurocentric interests (tenet 2) while delegitimizing or ignoring Indigenous epistemologies and stories (tenets 7 and 8). Furthermore, bordertown policies 
TABLE 3

Coding Procedures (Partial Sample)

\begin{tabular}{|c|c|}
\hline Procedure & Description \\
\hline $\begin{array}{l}\text { 1. Identify so- } \\
\text { cial actors }\end{array}$ & $\begin{array}{l}\text { For each policy, identify language that defines or describes the } \\
\text { following actors. Note examples that support Indigenous views (e.g., } \\
\text { recognition of extended family members in educational decision- } \\
\text { making). } \\
\text { - Students } \\
\text { - Parents/Guardians/Caregivers } \\
\text { - Administrators } \\
\text { - School Board Members/Trustees }\end{array}$ \\
\hline 2. Code text & $\begin{array}{l}\text { Identify language (sentences or phrases) appearing across multiple } \\
\text { districts ("boilerplate") and omit from further review. Code re- } \\
\text { maining text according to following descriptors. } \\
\text { - Property: Eurocentric/settler-colonial property ownership } \\
\text { expectations are upheld by nonresident applicant's connection } \\
\text { to physical property within district. } \\
\text { - Academic Success: Specific (e.g., test scores, GPAs, etc.) and nonspe- } \\
\text { cific (e.g., "motivation," "interest," etc.) descriptors privilege Euro- } \\
\text { centric expectations (e.g., competition, market-driven, test-based } \\
\text { accountability, etc.). } \\
\text { - Behavior and Attendance: Candidates provide proof of adherence } \\
\text { to Eurocentric behavior and attendance norms (e.g., eye } \\
\text { contact, answering when spoken to, absences only for reasons } \\
\text { approved by school leadership, etc.). Positive prior records } \\
\text { and future agreements may be required for admission. } \\
\text { - Proof of Assimilation: Once admitted, nonresident students are } \\
\text { expected to assimilate. Eurocentric norms (e.g., zero tolerance } \\
\text { policies, sustained GPAs, "proficient" performance on } \\
\text { assessments, etc.) define acceptable progress and potential for } \\
\text { continued enrollment. Note examples that hold nonresident } \\
\text { students to higher standards than resident students. } \\
\text { Power: Actors have different roles in terms of power, judgment, } \\
\text { and control. Admission procedures may reinforce Eurocentric } \\
\text { power/judgment/control (e.g., interviews, written behavior } \\
\text { contracts, legal documentation, etc.). Note types of decisions } \\
\text { and their weight (e.g., "final decisions," etc.). } \\
\text { - Self-Determination: Processes that respect Indigenous } \\
\text { epistemologies elevate the decision-making roles of students, } \\
\text { family members, and members of the community. Identify } \\
\text { opportunities for self-determined admission rationale/criteria, } \\
\text { advocacy, and monitoring (e.g., student-created plans, appeals } \\
\text { processes, family involvement, etc.). }\end{array}$ \\
\hline
\end{tabular}




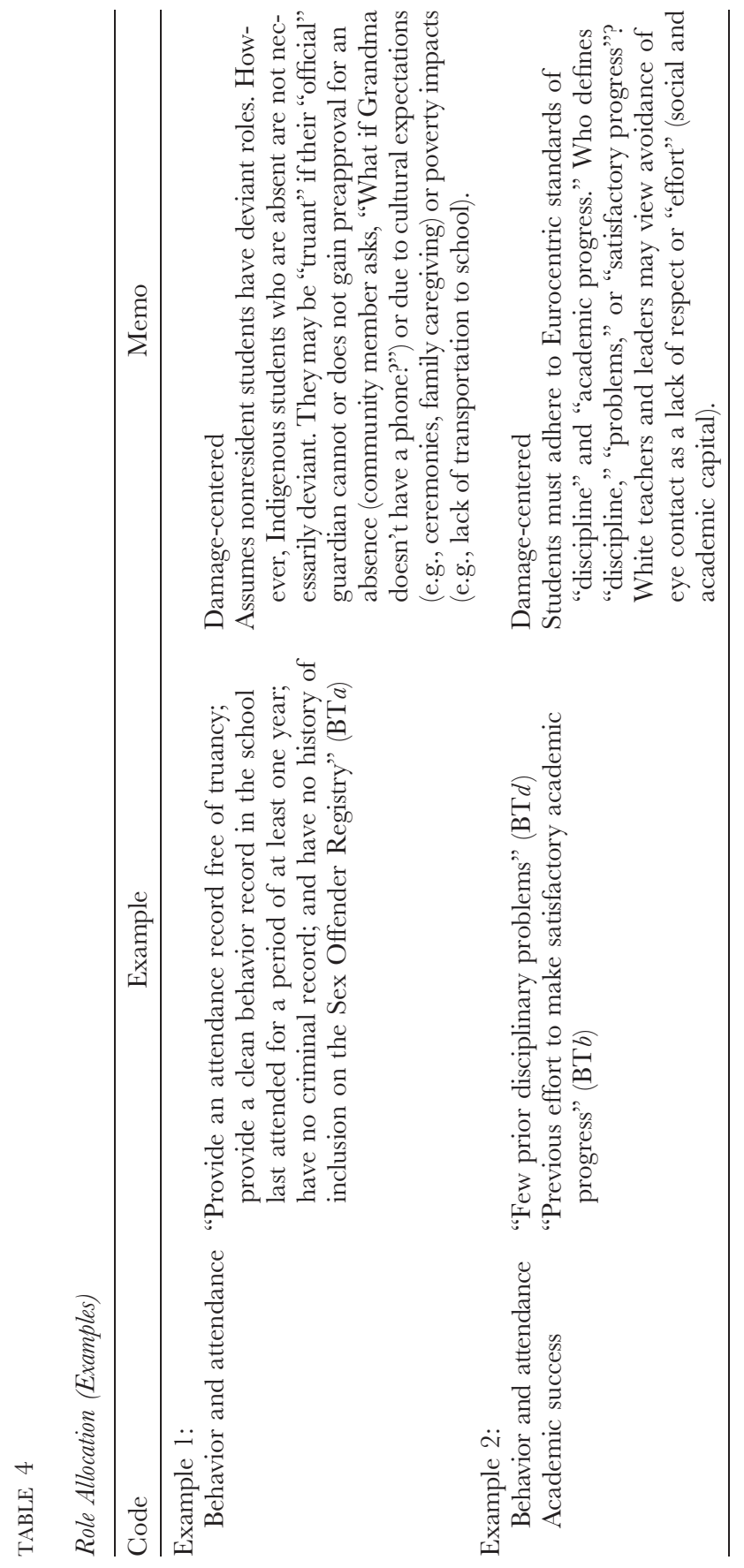




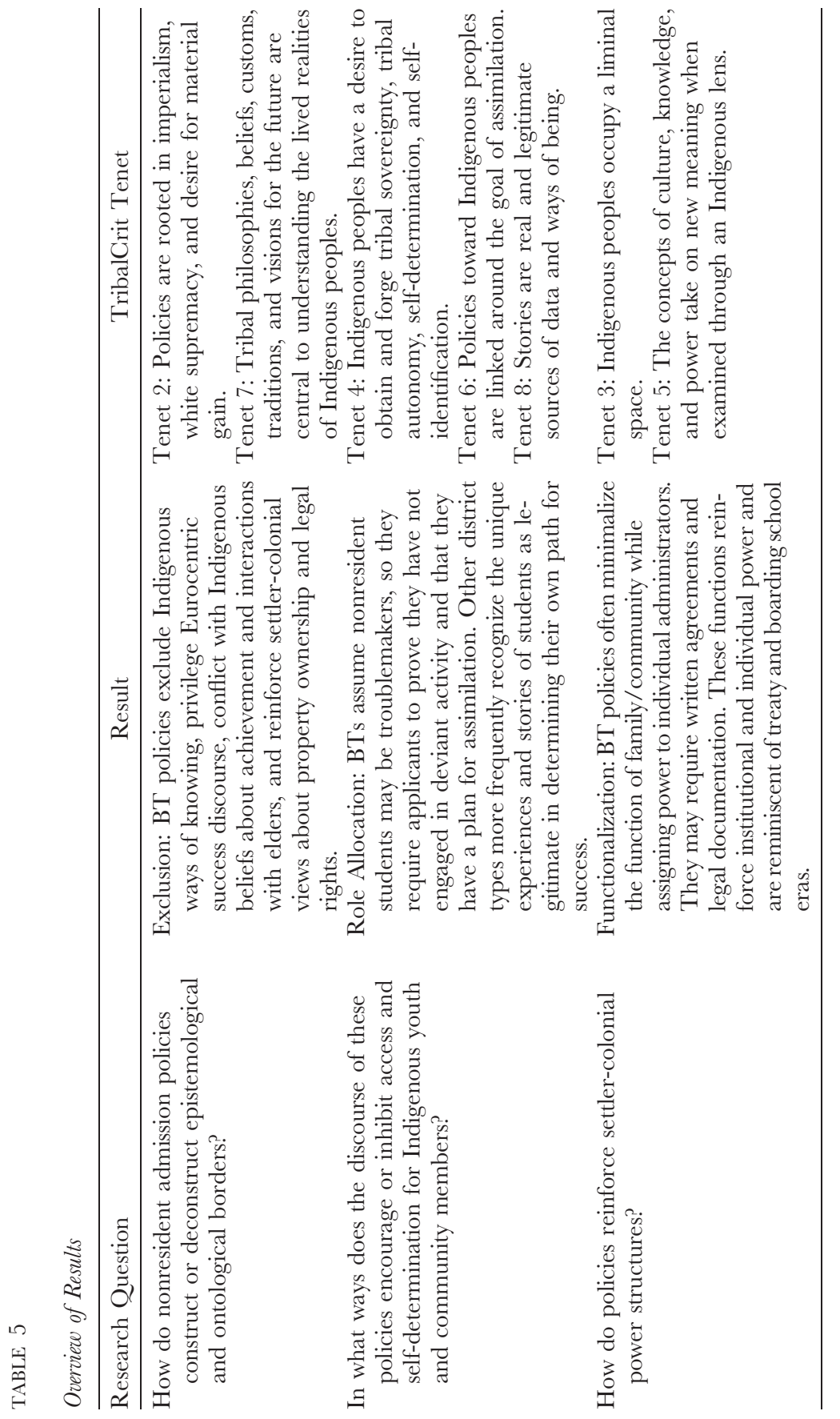

This content downloaded from 153.090.169.211 on August 26, 2019 13:06:04 PM All use subject to University of Chicago Press Terms and Conditions (http://www.journals.uchicago.edu/t-and-c). 
typically confine Indigenous peoples to "a liminal space" (Brayboy 2005, 429; tenet 3) through exclusion of an Indigenous lens (tenet 5) and restricted opportunities for self-determination (tenet 4). Below, descriptions of the results are presented as themes integrating van Leeuwen's (2008) representations of social actors with Brayboy's (2005) tenets of TribalCrit (table 5).

\section{Exclusion of Indigenous Epistemologies and Ontologies}

Many of the bordertown districts use exclusionary educational policies informed by assumptions of settler supremacy in terms of views of both physical and academic property (TribalCrit tenet 2). For example, bordertown districts often require nonresident students to demonstrate their intent to establish permanent residency in the district (i.e., have a legal connection to physical property within the district's boundaries or provide a plan to establish such a connection). In addition, nonresident students must prove their potential to successfully access academic property (e.g., have high test scores).

Policies from across the three district types include expectations for "good standing" related to prior academic performance, attendance, and behavior. However, whereas GD and RB district policies allow for inclusive interpretations of "good standing," bordertown districts describe specific procedures that privilege Eurocentric admission criteria. For example, BTe's district requires "an intake meeting ... to establish expectations for attendance, behavior and academic performance," and BT $a$ 's district requires standardized test scores in addition to other evidence of previous academic success. As a result, bordertowns may exclude Indigenous students who may view meetings with unfamiliar elders as culturally inappropriate and who may be less likely than their white peers to demonstrate proficiency on standardized tests. Within Indigenous contexts, the influence of standardized testing offers "the most recent challenge to Indigenous educational self-determination” (Lomawaima and McCarty 2006, xxiv).

Whereas bordertown district policies generally employ discourse that excludes students, GD district policies typically use discourse that reflects greater flexibility and inclusivity. For example, GDd's policy notes admission of any nonresident students "if the pupil desires to attend the school and if attendance ... would be more convenient or is desirable because of services available." However, not all GD districts use policies to demonstrate inclusivity. GD b's policy demands "necessary legal documents required by the District" to accompany the nonresident student's application. In the case of this district (and only this district), all students — resident and nonresident - are required to produce a Social Security card when enrolling or applying for admission. Given GDb's sizable migrant community, this unusual requirement raises questions about equity and access within all districts, including those that are GD from reservations.

FEBRUARY 2019 
Through overly subjective discourse, bordertown district policies use arbitrary criteria to exclude nonresident applicants. For example, BT $a$ 's policy emphasizes, "The District reserves the right to consider additional criteria in the event unforeseen circumstances or requests present themselves." In this example, the district is empowered while the student is excluded. In contrast, GD and RB districts use vague but active language to include rather than exclude potential students. For example, the GD $a, \mathrm{RB} a$, and GD $c$ policies note, "The District has the option of accepting a nonresident student who does not meet the criteria set forth by the administration, if the student agrees to special conditions of admission as set forth by the District." This example, which uses language very similar to that in BTa's policy, acknowledges the student as a social actor who has the agency to agree to, or choose not to agree to, "special conditions" defined by the district.

\section{Role Allocation: Restricting Indigenous Self-Determination}

Policy insiders often "mix" their descriptions of "structural inequities" with deficit discourse aimed at blaming underserved communities and students (Bertrand et al. 2015, 13). In very different ways, the district policies analyzed in this study allocate- or determine - roles through the assignment of real or perceived behaviors to individuals or groups (examples shown in table 4). Generally, bordertown districts enact a damage-centered (Tuck 2009) discourse that assumes nonresident students fill the role of deviants, whereas the GD and RB school districts create space for more diverse definitions of success. Most of the bordertown policies focus on accepting students who already adhere to - or prove they will transform into students who adhere to- the rules and norms of settler-colonial society (TribalCrit tenet 6). As CRT scholars note, "interest convergence" often drives educational policy making (Milner 2008). In the case of this study, bordertown districts are willing to admit Indigenous students if those students cross the border into the Eurocentric academic culture by providing proof of worthiness (i.e., good grades and behavior records) and ongoing acceptable performance (both academic and behavioral). In other words, nonresident applicants will be considered as long as they assimilate and advance a positive image of the district, a goal that echoes the "desire for material gain" inherent to settler-colonial policy making (Brayboy 2005, 429).

Although most of the policies note general academic- and behavior-oriented criteria, only bordertown districts articulate expectations regarding maintenance of specific grade point averages $(\mathrm{BT} a)$ or "a written agreement [establishing] the responsibilities of the student/parent/guardian and the school" (BTe). These indicators demonstrate the bordertown districts' tendency to priv-

\section{American Journal of Education}


ilege Eurocentric, settler-colonial measures of performance (i.e., grade point averages) and promise (i.e., written agreements). In several cases, bordertown district policies include requirements that further assume deviant behavior stereotypes, which echo historical discourse that frames the Indigenous other as primitive and savage. In contrast, GD and RB district policies engage a discourse that does not assume nonresident students may be criminals, deviants, or underperformers. In fact, three GD districts recognize "special conditions" that may allow admission to students who do not initially meet district policy criteria.

In terms of continued enrollment, nonresident students are not held to different standards compared with resident students in GD and RB districts. Bordertown districts, on the other hand, scrutinize nonresident students in terms of academics, behavior, and attendance in order to consider those students for continued enrollment after they have been initially admitted. For example, BT $b$ 's policy notes that continued attendance is contingent upon nonresident students "showing a strong desire to obtain an education." As Native children are often encouraged to remain humble and quiet within learning environments (Pewewardy 2002), teachers and administrators who believe students best demonstrate a strong desire through aggressive classroom participation might overlook Native students. They might also assume that avoidance of eye contact — which is a sign of respect in many Indigenous communities - is a display of poor behavior.

\section{Functionalization: Reinforcement of Settler-Colonialism through Liminal Positioning}

Within educational policy-making contexts, "discursive strategies can be tools to either maintain or challenge hierarchical relationships" (Bertrand et al. 2015, 4). Although the use of anonymous authors and legalese suggests objectivity, bordertown policies often empower institutional leaders and board members, who are almost exclusively white, while diminishing the function and power inherent to Indigenous community members, families, and students (TribalCrit tenet 5). Such claimed neutrality delegitimizes differences and identities while simultaneously reaffirming and normalizing settler-colonialism and white privilege (Fraise and Brooks 2015; Khalifa et al. 2016). Furthermore, marginalizing Indigenous peoples within decision-making processes reinforces liminality (TribalCrit tenet 3).

Frequently, bordertown district policies suggest a nearly omnipotent function of the superintendent. Four bordertown districts assign "authority" or "sole discretion" regarding nonresident student admission and retention to that individual administrator. For example, BTe's policy states, "The Superintendent 


\section{Educational Manifest Destiny}

is authorized to approve admission for an out of district student, and the Board must ratify that decision at the next regular meeting of the Board." This wording not only allocates initial power to the superintendent, but the use of "must ratify" also suggests the board's power is limited, passive, and largely symbolic. BTb's policy frames the function of superintendent as active and aggressive: "the Superintendent of Schools has the authority to terminate the acceptance of nonresident students at any time for any reason." Because most bordertown administrators are white, this is a particularly important finding.

In contrast, GD and RB districts employ discourse that expands decisionmaking power to multiple individuals. Districts $\mathrm{GD} a, \mathrm{RB} a, \mathrm{GD} c, \mathrm{GD} e$, and $\mathrm{RB} e$ note that the superintendent can "recommend" nonresident student admission but that the decision rests with the board of trustees. RB $d$ 's policy suggests that the board and superintendent share power: "The Board of Trustees may authorize the Superintendent to admit or not admit." Instead of an individual, GD and RB school districts demonstrate an interest in collective decision making. This approach is beneficial for two reasons: (1) it allows student applications to be considered by several individuals who are themselves community members and elected officials, and (2) it supports traditional, collective leadership models common to many Indigenous communities.

The districts also view the function of family and other community members very differently. Bordertown and GD districts tend to use "parent" or "parent/ guardian" exclusively when referring to adult caregivers. This is problematic given the traditional role of multiple family and community members in raising children within many Indigenous communities. It is common, for instance, for Native children to spend part of their time living with grandparents, aunts, or uncles to receive cultural or behavioral guidance. Four of the districts $(\mathrm{RB} b$, $\mathrm{RB} c, \mathrm{RB} d$, and $\mathrm{BT} d$ ) acknowledge the function of adults other than parents/ guardians in terms of educational decision making about specific students. Each district includes a provision for "responsible adult" caregivers who may not be the student's parent or legal guardian, although the districts define that adult differently. $\mathrm{RB} b$ and $\mathrm{RB} d$ require this adult to "sign a consent form," whereas $\mathrm{RB} c$ and $\mathrm{BT} d$ require a "legal consent document" or "legal custody papers." Although $\mathrm{RB} c$ allows notarized or witnessed paperwork, BT $d$ notes that a "simple document prepared by the parent and notarized does not meet the district's requirement of legal consent." To adhere to the policy, BT $d$ requires designation of custody by an attorney or a court-ordered placement. Given the legacy of broken treaties and inappropriate treatment of children by employees of the state, such legal documents and actions are viewed with suspicion in many Indigenous communities. In addition, since BT $d$ will not accept a notarized or witnessed statement as a legal document, it is likely that families and caregivers would encounter legal fees, time commitments, and other obstacles in order to secure the acceptable paperwork. 
Implications and Recommendations

To enhance access for Indigenous peoples, careful attention to the integration of theory, story, practice, and action is needed, as outlined in TribalCrit's final tenet: "Theory and practice are connected in deep and explicit ways such that scholars must work toward social change" (Brayboy 2005, 430). In particular, studies that apply CDA, such as the one shared in this article, may support transformation, as they offer the potential to "shine a light on differences in educational experiences" (Bertrand et al. 2015, 23). However, "policy insiders ... can choose to acknowledge the systemic inequity in education or overlook it" (Bertrand et al. 2015 , 3). Shifting from "damage-centered" to "desire-centered" policy discourse and practice requires recognition of the endemic and complicated nature of racism (TribalCrit tenet 1), as well as the "complexity, contradiction, and the self-determination of lived lives" (Tuck 2009, 416).

Although settler-colonialism is endemic to society in the United States, it is important for district leaders to avoid "explain[ing] away systemic racism as a natural occurrence" (Bertrand et al. 2015, 21) to excuse their own inaction. Dismantling institutional racism is difficult work, as it obligates district leaders and policy makers to practice self-awareness, ensure culturally responsive curricula and teacher preparation, promote inclusive school environments, and engage students and parents in community contexts (Khalifa et al. 2016). Because many institutional leaders - who are predominantly white middle- to upper-class males - may not often cross physical, political, and cultural borders themselves, it is vital that district leaders and policy makers receive training aimed at helping them confront settler-colonial paradigms while providing a space for peoples of color to share their unique cultural worldviews (Bird et al. 2013; Carjuzaa and Ruff 2010; Henderson et al. 2015; Ottman 2009).

Ongoing consultation with members of local Indigenous communities is also needed to "destabilize dominant policy discourses" (McCarty and Lee 2014, 103). In particular, community members of color, as "the experts on their lived experiences" (Bertrand et al. 2015, 24), should be active participants in the (re)visioning of education policy. Advisory groups can contribute to a district's continued effectiveness in terms of honoring Indigenous views within policy making (Quijada Cerecer 2013). Community representatives in policy making should extend beyond parents (and other caregivers), as research suggests that parent preferences themselves can reinforce racial segregation within school choice decision making (Phillips et al. 2015). In addition, it is common for school leaders to assign consultation roles to community members they already know (or have influence over). Instead of token inclusion or superficial consultation, Indigenous peoples should serve as valuable partners "at all stages of decision and policy development" (Ottman 2009, 6).

FEBRUARY 2019 


\section{Educational Manifest Destiny}

In addition to adult involvement, research suggests that youth of color might benefit from involvement in policy making, including development and implementation of restorative justice practices (Skiba 2014; Winn and Winn 2015). However, some scholars argue that the restorative justice movement neglects the systemic and endemic nature of racism and that it is "invoked only when colonial power structures deem it advantageous to do so" (Breton 2011). "People-topeople healing" (Breton 2011), where meaningful dialogue provides accountability so that both victims and perpetrators of harm can experience healing, is vital to ensure transformation extends beyond interest convergence-generated change. Development of youth advisory councils might offer another opportunity for students to contribute to the change process with integrity.

Scheurich et al. (2017) recommend development of district, state, and national policies that recognize and cultivate "community-based definitions of equitable education" (523). The community-based framework for educational equity offered by Scheurich et al. (2017) can provide a starting point for analysis and development of inclusive educational policies. Within this framework, marginalized communities define educational equity for themselves, with attention to democratic ideals, unique place-based context, and awareness of the influence of societal and historical changes on the community and its schools. Specifically, as they draft admission policies, policy makers should "include provisions for transportation and priorities for students making integrative moves, alongside prohibitions against academic or behavioral criteria that screen students out" (Frankenberg et al. 2017, 460).

The TribalCrit tenets themselves can provide border-crossing guidance for leaders, policy makers, and educational researchers in schools that serve Indigenous students. Within the unique contexts of reservation bordertowns, policy makers should seek legal guidance from experts in tribal law and policy, as they may not realize that federal-level educational self-determination policies apply to them. Although most educational decision making is the domain of states and local districts, tribes are unique in their status as sovereign governments, and their members are guaranteed protections, regardless of whether they are on tribal lands (Reinhardt 2004). In particular, reservation bordertowns and $\mathrm{RB}$ schools offer an "important and unique context for understanding the meaning and processes of school choice because of the government-to-government relationship between tribal nations, the nation-building goals of tribes, and the assimilationist history of schooling options within Native communities" (Castagno et al. 2016, 228).

Furthermore, including legal experts and Indigenous partners throughout policy-making processes also ensures that "decisions and policies are owned by all stakeholders, increasing the chances for success" (Ottman 2009, 6). For example, creating space for legal experts, leaders, and community members to open a dialogue about Indigenous perspectives of family, relationality, and

\section{American Journal of Education}


informal education could help shape culturally responsive and legally supported policy related to caregiver roles and school-family communication. As TribalCrit scholars emphasize, examining concepts such as knowledge and power through an Indigenous lens builds new understandings while advancing Indigenous peoples' own desire to "forge tribal sovereignty, tribal autonomy, selfdetermination, and self-identification" (Brayboy 2005, 429).

This study offers several important implications for future research. First, it demonstrates the need for in-depth study into policy making and its effects, both in terms of the policy discourse itself and the covert "discursive strategies" (Bertrand et al. 2015, 7) that underlie such work. Case studies of school districts in areas with rapidly changing demographics - including those in rural contexts - could provide added insight to the potential for admission policies to reinforce segregation and racism. Furthermore, research into inter- and intradistrict enrollment and mobility is needed to determine the ways that "districts of choice," which allow students to enroll in any school within the district, encourage or inhibit inclusivity of cultural ways of knowing. In particular, case studies of reservation bordertowns would be helpful in terms of determining perspectives of various leaders and stakeholders. For example, an administrator suggested that BTb's detailed and stringent nonresident student admission policy is in place because its schools are over capacity and that school leaders "try to let in as many students as possible." Yet teachers, parents, and students in that district note empty seats in almost all grades.

\section{Conclusion}

US policy makers have long used physical and cultural boundaries to exclude peoples of color, promote assimilation, and protect settler-colonial constructions of property and progress (Brayboy 2005; Quijada Cerecer 2013). In particular, as Faircloth and Tippeconnic (2013) note, "The policies and practices of formal education for American Indians, Alaska Natives, and other Indigenous peoples across the world have been characterized by a colonizing (i.e., hegemonic, assimilationist, acculturating) and oppressive approach to education" (483). Immediate attention and action are important given the widening opportunity gap between white students and youth of color, the devastating influence of violence and racism against Indigenous peoples in bordertowns, the escalating rates of health and economic disparities in American Indian communities, and the accelerated erosion of cultural knowledges. As Smith (1999) emphasizes, "The surface story was not as important as the underlying examples of cultural protocols broken, values neglected, small tests failed and key people ignored. The greater danger, however, was in the creeping policies that intruded into every aspect of our lives" (3).

FEBRUARY 2019 


\section{Educational Manifest Destiny}

As this study demonstrates, there is potential for reservation bordertown policies to exclude Indigenous perspectives, allocate stereotypical roles to Indigenous students to limit self-determination, and restrict the function of Indigenous peoples while fortifying settler-colonial power. Continued attention needs to be given to "the creeping policies" regulating student admission throughout various types of districts, particularly as school choice initiatives have proven unsuccessful in their efforts to simultaneously "liberate students from lowperforming schools and reduce stratification" (Phillips et al. 2015, 48). Although Lomawaima and McCarty (2006) recognize the potential for "Native-operated charter schools" to challenge settler-colonialism by "mediating the pressures of the standards movement and exerting local control" (162), they also caution that the school choice movement may undermine efforts to advance justice within noncharter public schools. Educational equity requires culturally responsive practice, policy making, and leadership — as actively shaped by communities of color - throughout all schools, including charter schools and conventional public schools, reservation communities and bordertown schools, and urban and rural districts.

\section{Notes}

I am thankful to my partners and mentors, especially those from across Indian Country, who urged me to engage in this research and who provided guidance throughout the process of data collection and analysis.

1. Although use of specific Indigenous nation names is preferable to general terms, such use could compromise confidentiality in this study, given the small size of Indigenous communities. For this article, multiple terms (e.g., American Indian, Native, Native American, and Indigenous) suggested by participants in this and earlier studies are used interchangeably to demonstrate both unity and diversity across and within Indigenous groups.

2. In March 2017, state 2's legislature passed a bill to require K-12 social studies educators to teach all students about Indigenous histories and experiences. Although not as comprehensive as state 1's mandate (which requires teaching about Indigenous perspectives and experiences across grade levels and subject areas), the legislation marks a significant change in thinking about the inclusion of Indigenous experiences within schools and curricula.

\section{References}

Ahn, June, and Andrew McEachin. 2017. "Student Enrollment Patterns and Achievement in Ohio's Online Charter Schools." Educational Researcher 46 (1): 44-57.

Ambler, Marjane. 2009. "Tribal Colleges Tackle Education for All." Tribal College $21(2): 10-11$.

\section{American Journal of Education}


Anyon, Yolanda, Duan Zhang, and Cynthia Hazel. 2016. "Race, Exclusionary Discipline, and Connectedness to Adults in Secondary School." American fournal of Community Psvchologv 57:342-52.

Anzaldúa, Gloria. 2007. Borderlands/La Frontera: The New Mestiza. 3rd ed. San Francisco: Aunt Lute.

Archibald, Jo-ann. 2008. Indigenous Storywork: Educating the Heart, Mind, Body, and Spirit. Vancouver: University of British Columbia Press.

Bertrand, Melanie, Wendy Perez, and John Rogers. 2015. "The Covert Mechanisms of Education Policy Discourse: Unmasking Policy Insiders' Discourses and Discursive Strategies in Upholding or Challenging Racism and Classism in Education." Education Policy Analysis Archives 23 (93): 1-31. https://files.eric.ed.gov/fulltext/EJ1084085.pdf.

Bird, Carlotta, Tiffany Lee, and Nancy Lopez. 2013. "Leadership and Accountability in American Indian Education: Voices from New Mexico." American fournal of Education 119:539-64.

Brayboy, Bryan McKinley Jones. 2005. "Toward a Tribal Critical Race Theory in Education." Urban Review 37 (5): 425-46.

Brayboy, Bryan McKinley Jones, and Angela Castagno. 2009. "Self-Determination through Self-Education: Culturally Responsive Schooling for Indigenous Students in the USA." Teaching Education 20 (1): 31-53.

Brayboy, Bryan McKinley Jones, Heather Gough, Beth Leonard, Roy Roehl, and Jessica Solyom. 2012. "Reclaiming Scholarship: Critical Indigenous Research Methodologies." In Qualitative Research: An Introduction to Methods and Designs, ed. Stephen Lapan, Lynn Quartaroli, and Frances Riemer. San Francisco: Jossey-Bass.

Breton, Denise. 2011. "Decolonizing Restorative Justice." Unsettling America, September 13, https://unsettlingamerica.wordpress.com/2011/09/13/decolonizing -restorative-justice/.

Carjuzaa, Jioanna. 2012. "The Positive Impact of Culturally Responsive Pedagogy: Montana's Indian Education for All." International Fournal of Multicultural Education 14 (3): $1-17$.

Carjuzaa, Jioanna, Anna Baldwin, and Michael Munson. 2015. "Making the Dream Real: Montana's Indian Education for All Initiative Thrives in a National Climate of Anti-Ethnic Studies." Multicultural Perspectives 17 (4): 198-206.

Carjuzaa, Jioanna, and William Ruff. 2010. "When Western Epistemology and an Indigenous Worldview Meet: Culturally Responsive Assessment in Practice." Fournal of Scholarship of Teaching and Learning 10 (1): 68-79.

Carlson, Deven. 2014. "School Choice and Educational Stratification." Policy Studies Zournal 42 (2): 269-304.

Castagno, Angelina, David Garcia, and Nicole Blalock. 2016. "Rethinking School Choice: Educational Options, Control, and Sovereignty in Indian Country." Zournal of School Choice 10 (2): 227-48.

Cornbleth, Catherine. 2006. "Curriculum and Students: Diverting the Public Interest." In Education Research in the Public Interest, ed. G. Ladson-Billings and W. Tate. New York: Teachers College Press.

Deloria, Vine, Jr., and Daniel Wildcat. 2001. Power and Place: Indian Education in America. Golden, CO: Fulcrum Resources.

Deyhle, Donna. 1986. "Break Dancing and Breaking Out: Anglos, Utes, and Navajos in a Border Reservation High School." Anthropology and Education Ouarterlv 17 (2): 111 27.

Doll, Jonathan, Zohreh Eslami, and Lynne Walters. 2013. "Understanding Why Students Drop Out of High School, According to Their Own Reports: Are They

FEBRUARY 2019 


\section{Educational Manifest Destiny}

Pushed or Pulled, or Do They Fall Out? A Comparative Analysis of Seven Nationally Representative Studies." SAGE Open 3 (4). doi:10.1177/2158244013503834.

Estes, Nick. 2014a. "Border Town, USA: An Ugly Reality Many Natives Call Home." Indian Country Today, August 15, http://indiancountrytodaymedianetwork.com/2014 /08/15/border-town-usa-ugly-reality-many-natives-call-home-156414.

Estes, Nick. 2014b. "Chamberlain, South Dakota: A Border Town and Its 'Indian Problem.'” Indian Country Today, June 25, http://indiancountrytodaymedianetwork.com /2014/06/25/chamberlain-south-dakota-border-town-and-its-indian-problem.

Faircloth, Susan, and John Tippeconnic III. 2013. "Leadership in Indigenous Education: Challenges and Opportunities for Change." American Fournal of Education 119:481-86.

Fairclough, Norman. 1992. Discourse and Social Change. Malden, MA: Polity.

Figlio, David, and Krzysztof Karbownik. 2016. Evaluation of Ohio's EdChoice Scholarship Program: Selection, Competition, and Performance Effects. Columbus, OH: Fordham Institute.

Forbes, Jack. 1998. "Intellectual Self-Determination and Sovereignty: Implications for Native Studies and for Native Intellectuals." Wicazo Sa Reviere 13 (1): 11-23.

Fraise, Nicole, and Jeffrey Brooks. 2015. "Toward a Theory of Culturally Relevant Leadership for School-Community Culture." International Fournal of Multicultural Education 17 (1): 6-21.

Francis, Lee, and Michael Munson. 2017. "We Help Each Other Up: Indigenous Scholarship, Survivance, Tribalography, and Sovereign Activism." International Fournal of Oualitative Studies in Education 30 (1): 48-57.

Frankenberg, Erica, Genevieve Siegel-Hawley, and Sarah Diem. 2017. "Segregation by District Boundary Line: The Fragmentation of Memphis Area Schools.” Educational Researcher 46 (8): 449-63.

Freire, Paulo. 1985. The Politics of Education: Culture, Power, and Liberation. Boston: Bergin \& Garvey.

Gay, Geneva. 2000. Culturally Responsive Teaching: Theory, Research, and Practice. New York: Teachers College Press.

Gee, James. 2005. An Introduction to Discourse Analysis: Theory and Method. New York: Routledge.

Giroux, Henry. 1992. "Paulo Freire and the Politics of Postcolonialism." Fournal of Advanced Composition 12 (1): 15-26.

González, Norma, Luis Moll, and Cathy Amanti. 2005. Funds of Knowledge: Theorizing Practice in Households, Communities, and Classrooms. Mahwah, NJ: Erlbaum.

Grande, Sandy. 2004. Red Pedagogy: Native American Social and Political Thought. New York: Rowman \& Littlefield.

Grande, Sandy. 2008. "Red Pedagogy: The Un-Methodology." In The Handbook of Critical and Indigenous Methodologies, ed. Norman Denzin, Yvonna Lincoln, and Linda Tuhiwai Smith. Los Angeles: Sage.

Harris, Cheryl. 1993. "Whiteness as Property." Harvard Law Reviewe 106 (8): 1710-91.

Henderson, David, Jioanna Carjuzaa, and William Ruff. 2015. "Reconciling Leadership Paradigms: Authenticity as Practiced by American Indian School Leaders." $\underline{\underline{I n}}$ ternational Fournal of Multicultural Education 17 (1): 211-31.

Khalifa, Muhammad, Mark Gooden, and James Davis. 2016. "Culturally Responsive School Leadership: A Synthesis of the Literature." Review of Educational Research 86 (4): 1272-311.

Knoester, Matthew, and Wayne Au. 2017. "Standardized Testing and School Segregation: Like Tinder for Fire?" Race. Ethnicity and Education 20 (1): 1-14. 
Kovach, Margaret. 2013. "Treaties, Truths, and Transgressive Pedagogies: Re-imagining Indigenous Presence in the Classroom." Socialist Studies 9 (1): 109-27.

Ladson-Billings, Gloria, and William Tate IV. 1995. "Toward a Critical Race Theory of Education." Teachers College Record 97 (1): 47-68.

Lomawaima, K. Tsianina. 2004. "Educating Native Americans." In The Handbook of Research on Multicultural Education, 2nd ed., ed. James Banks and Cherry McGee Banks. San Francisco: Jossey-Bass.

Lomawaima, K. Tsianina, and Teresa McCarty. 2006. To Remain an Indian: Lessons in Democracy from a Century of Native American Schooling. New York: Teachers College Press.

Lugg, Catherine, and Alan Shoho. 2006. "Dare Public School Administrators Build a New Social Order?" Fournal of Educational Administration 44 (3): 196-208.

McCarty, Teresa, and Tiffany Lee. 2014. "Critical Culturally Sustaining/Revitalizing Pedagogy and Indigenous Education Sovereignty.” Harvard Educational Review 84 (1): 101-24.

McCarty, Teresa, Mary Romero-Little, and Ofelia Zepeda. 2006. "Native American Youth Discourses on Language Shift and Retention: Ideological Cross-Currents and Their Implications for Language Planning." International fournal of Bilingual Education and Bilingualism 9 (5): 659-77.

Mills, Jonathan, Anna Egalite, and Patrick Wolf. 2016. How Has the Louisiana Scholarship Program Affected Students?: A Comprehensive Summary of Effects after Two Years. New Orleans: Education Research Alliance for New Orleans.

Milner, H. Richard. 2007. "Race, Culture, and Researcher Positionality: Working through Dangers Seen, Unseen, and Unforeseen." Educational Researcher 36 (7): 388400.

Milner, H. Richard. 2008. "Critical Race Theory and Interest Convergence as Analytic Tools in Teacher Education Policies and Practices." Fournal of Teacher Education 59 (4): 332-46.

Ottman, Jacqueline. 2009. "Leadership for Social Justice: A Canadian Perspective." Fournal of Research on Leadership Education 4 (1): 1-9.

Padgett, Gary. 2012. "A Critical Case Study of Selected United States History Textbooks from a Tribal Critical Race Theory Perspective." PhD diss., University of South Florida.

Paris, Django. 2012. "Culturally Sustaining Pedagogy: A Needed Change in Stance, Terminology, and Practice." Educational Researcher 41 (3): 93-97.

Penfield, Randall, and Okhee Lee. 2010. "Test-Based Accountability: Potential Benefits and Pitfalls of Science Assessment with Student Diversity." Zoumal of Research in Science Teaching 47 (1): 6-24.

Perry, Barbara. 2009. "There's Just Places Ya' Don't Wanna Go: The Segregating Impact of Hate Crime against Native Americans." Contemporarn fustice Review 12 (4): 401-18.

Pewewardy, Cornel. 2002. "Learning Styles of American Indian/Alaska Native Students: A Review of Literature and Implications for Practice." Fournal of American Indian Education 41 (3): 22-56.

Phillips, Kristie, Elisabeth Larsen, and Charles Hausman. 2015. "School Choice and Social Stratification: How Intra-District Transfers Shift the Racial/Ethnic and Economic Composition of Schools." Social Science Research 51:30-50.

Porter, Maureen. 2015. "Somos Incas: Enduring Cultural Sensibilities and Indigenous Education." In Indigenous Education: Language, Culture, and Identity, ed. W. James Jacob, Sheng Yao Cheng, and Maureen Porter. New York: Springer. 


\section{Educational Manifest Destiny}

Quijada Cerecer, Patricia. 2013. "The Policing of Native Bodies and Minds: Perspectives on Schooling from American Indian Youth." American Fournal of Education 119 (4): 591 616.

Reinhardt, Martin. 2004. "A Comparative Socio-Historical Content Analysis of Treaties and Current American Indian Education Legislation with Implications for the State of Michigan." PhD diss., Pennsylvania State University.

Reisigl, Michael, and Ruth Wodak. 2009. "The Discourse-Historical Approach." In Methods of Critical Discourse Analysis, 2nd ed., ed. Ruth Wodak and Michael Meyer. London: Sage.

Rogers, Christine, and Angela Jaime. 2010. "Listening to the Community: Guidance from Native Community Members for Emerging Culturally Responsive Educators." Equitv and Excellence in Education 43 (2): 188-201.

Rogers-Ard, Rachelle, Christopher Knaus, Kitty Epstein, and Kimberly Mayfield. 2012. "Racial Diversity Sounds Nice; Systems Transformation? Not So Much: Developing Urban Teachers of Color." Urban Education 48 (3): 451-79.

Sanchez, Tony. 2007. "The Depiction of Native Americans in Recent (1991-2004) Secondary American History Textbooks: How Far Have We Come?" Equity and Excellence in Education 40 (4): 311-20.

Santamaria, Lorri, and Andres Santamaria. 2015. "Counteracting Educational Injustice with Applied Critical Leadership: Culturally Responsive Practices Promoting Sustainable Change." International Fournal of Multicultural Education 17 (1): 22-41.

Scheurich, James, Vicki Bonds, Jada Phelps-Moultrie, Brandon Currie, Troy Crayton, Alycia Elfreich, Catherine Bhathena, Tiffany Kyser, and Nathaniel Williams. 2017. "An Initial Exploration of a Community-Based Framework for Educational Equity with Explicated Exemplars." Race, Ethnicitv, and Education, 20 (4): 508-26.

Scheurich, James, and Michelle Young. 1997. "Coloring Epistemologies: Are Our Research Epistemologies Racially Biased?” Educational Researcher 26 (4): 4-16.

Shear, Sarah, Ryan Knowles, Gregory, Soden, and Anthony Castro. 2015. "Manifesting Destiny: Re/presentations of Indigenous Peoples in K-12 US History Standards." Theorv and Research in Social Education 43 (1): 68-101.

Siegel-Hawley, Genevieve. 2013. "Educational Gerrymandering? Race and Attendance Boundaries in a Demographically Changing Suburb." Harvard Educational Review 83 (4): 580-612.

Skiba, Russell J. 2014. "The Failure of Zero Tolerance." Reclaiming Children and Touth 22 (4): 27-33.

Smith, Linda Tuhiwai. 1999. Decolonizing Methodologies: Research and Indigenous Peoples. New York: Zed.

Souto-Manning, Mariana. 2014. "Critical for Whom? Theoretical and Methodological Dilemmas in Critical Approaches to Language Research." In Humanizing Research: Decolonizing Qualitative Inquiry with Youth and Communities, ed. Django Paris and Maisha Winn. Los Angeles: Sage.

Stanton, Christine Rogers. 2014. "Crossing Methodological Borders: Decolonizing Community-Based Participatory Research." Oualitative Inquiry 20 (5): 573-83.

Stein, Marc. 2015. "Public School Choice and Racial Sorting: An Examination of Charter Schools in Indianapolis." American Fournal of Education 121 (4): 597-627.

Tuck, Eve. 2009. "Suspending Damage: A Letter to Communities." Harvard Educational Review 79 (3): 409-27.

US Bureau of the Census. 2010. "Decennial Census Datasets: 2010." https://www .census.gov/programs-surveys/decennial-census/data/datasets.2010.html. 
van Leeuwen, Theo. 2008. Discourse and Practice: New Tools for Critical Discourse Analysis. New York: Oxford University Press.

Walter, Maggie, and Chris Anderson. 2013. Indigenous Statistics: A Quantitative Research Methodology. Walnut Creek, CA: Left Coast.

Whitford, Denise, and Deborah Levine-Donnerstein. 2014. "Office Disciplinary Referral Patterns of American Indian Students from Elementary through High School." Behavioral Disorders 39 (2): 78-88.

Williams, Sharon. 2013. "Outsider Teacher/Insider Knowledge: Fostering Mohawk Cultural Competency for Non-Native Teachers." Teacher Education Quarterly 40 (1): 25-43.

Wilson, Shawn. 2008. Research Is Ceremony: Indigenous Research Methods. Halifax: Fernwood.

Winn, Lawrence, and Maisha Winn. 2015. "Expectations and Realities: Education, the Discipline Gap, and the Experiences of Black Families Migrating to Small Cities." Race and Social Problems 7:73-83.

Yazzie, Melanie. 2014. "Brutal Violence in Border Towns Linked to Colonization." Indian Country Today, August 22, http://indiancountrytodaymedianetwork.com/2014/08/22 /violence-common-sense-natives-living-border-town-usa-156532?page $=0 \% 2 \mathrm{C} 0$. 